\title{
Application of Stone as a Roofing in the Reconstruction and Construction
}

\author{
Nenad Šekularac, Jelena Ivanović Šekularac and Jasna Čikić Tovarović \\ Faculty of Architecture, University of Belgrade, Belgrade 11000, Serbia
}

\begin{abstract}
In architecture, in the past, different materials were used for covering of the buildings. The selection of the type of roofing depended on the purpose and size of the building; thus all the churches, administrative buildings and important medieval buildings were originally covered with stone or lead slabs as the final roofing material. The tendency of return of stone as an authentic roofing in the reconstruction of medieval buildings and churches, as well as the introduction of stone as a roofing on the new buildings in protected historic cores, is possible only if fulfilled modern principles and requirements of the physics of construction. The application of modern principles of double ventilated roofs and the use of stone as a roofing enables the restoration and preservation of the original appearance of medieval buildings, as well as the preservation and conservation of existing frescoes that have been present for centuries in these facilities. It also enables a successful reconstruction of a large number of medieval buildings. In this way it has been given a contribution to the preservation of old medieval buildings as the improvement of world cultural heritage.
\end{abstract}

Key words: Stone slabs, double ventilation of roofs, reconstruction of medieval buildings.

\section{Introduction}

The geostrategic position of the Balkan Peninsula influenced the development of its countries, located at the crossroads of The East and West between Europe and The Middle Asia. This was the place where different cultures and heritages met, the exchange of knowledge and ideas as well as of scientific achievements and experiences of the time happened, undoubtedly influencing both the architecture and building of that period.

The building skills of people in Medieval Serbia was at a very high level, which is proved by the many buildings of that period that have been preserved until the present day. The construction technique of that time was very developed as well as the whole Medieval culture and science in the whole Balkan Peninsula. Only in some old scripts and drawings preserved on the walls of churches, can we find the proof of the existence of some buildings.

Corresponding author: Nenad Šekularac, associate professor, $\mathrm{PhD}$, research fields: design of architectural constructive structures and reconstruction of buildings. E-mail: nseki@sezampro.rs.

\section{Materials Used for Covering Medieval Buildings}

In the middle ages, in the Balkans — south part of Europe, different types of materials were used as a roof covering on the buildings of that period. Many of these buildings have been destroyed, and the only evidence of existence of some of these buildings are ruins that have left. Few buildings have been preserved.

The proof of application of different roof covering materials on the buildings of that period we can find in numerous frescos preserved in churches and monasteries built at that time. The frescos showing ktitors-founders (people who financed the construction of the buildings mentioned) holding a display model of the building they were erecting.

Unknown painters tried to keep the original look of the buildings in their drawings using different colors. In that way a roof painted red signifies a roof covered with terra-cotta products (clay tile and mission tile), a blue roof represents a roof covered with lead, brown is the roof covered with wood and grey was used for stone roof covering. 
The type of a cover used depended on the purpose and the size of buildings. Churches, administration buildings and all other important buildings were originally covered with slate and lead slate. Apart from these materials, wood and products made of terra-cotta (clay tile and mission tile) were also used as a roof cover [1].

\subsection{The Application of Wood as the Main Roofer}

What we know with certainty is that wooden roofers are very old, but we cannot precisely determine their age. There are no archeological remains which might provide direct evidence. Specific climate, very cold winters and hot summers with large fluctuation of temperature and high humidity, had an adverse influence on durability of wood as a material.

The oldest data on wood as a roofer which can be accepted as reliable comes from 14th century [2] and represents an image of buildings, covered by plates in regular rows incised on "stećak" (medieval tombstone). Apparently this roofer fits the description of the roof made of wood cladding. The evidence on wood cladding as a roofer also dates from the end of the first part of 14th century, shown in several founder's (ktitor's) models in monastery Morača in Montenegro. On the fresco the roof of this church was painted olive green with black diagonal lines. The roof of the monastery, covered with a wood cladding, is represented in this way. This type of a wooden roofer was not used on ordinary buildings. Nowadays it has been kept only on wooden churches.

\subsection{The Application of Lead Sheets as the Main Roofer}

In the middle ages, Serbia was well-known for its mineral wealth and numerous mines. There were a lot of lead and silver mines in Serbia so their production was bigger and they were used more for covering important and big buildings of that time. Most often lead sheets were used as a roof covering on most churches, monasteries and towers of medieval towns.
These lead sheets were the best and top-quality material as well as the most expensive, for covering the roofs of the first class buildings in Medieval Serbia. Apart from lead sheets the vaults of churches were also coated with lead strips.

There were two ways of lead sheets roofing: directly on dome arch or over a sheathing.

\subsection{The Application of Terra-cotta Brick Products as the Main Roofer}

Brick products, clay tile and mission tile, were used for covering smaller churches. As evidence of this type of a roof, we have the remnants of the old tiles preserved on some buildings. Their shape resembles the shape of the tiles which were used in Roman architecture. Some examples show us that there were glazed mission tiles, coloured ones, which were used for covering some buildings within monastery complexes.

\subsection{The Application of Stone as the Main Roofer}

Some churches and secular buildings of that period were covered with other materials. Smaller churches and other buildings within a monastery complex were often covered with slate. It is supposed that the oldest medieval buildings, in most cases, originally had slate as the final covering. During the Middle Ages in Serbia, the buildings covered with this slate were actually covered with rough stone plates $5 \mathrm{~cm}$ thick. Application of these plates on representative buildings of that period required their greater processing. Therefore, the thickness of dressed plates is less than 3 $\mathrm{cm}$.

The examples of slate roof covering have remained even until nowadays on Holy Mount, on Athos, in Greece. The name of Holy Mount appeared in the world of Eastern Christianity, when Athos began to follow the idea of creating the most important monastic community of that world. Holy Mount of Athon, as some call it, for more than 1,000 years, has been the most important religious and educational centre of the 
whole Orthodox East and in the following centuries it has entered the cultural inheritance of mankind.

Hilandar Monastery, the fourth in the hierarchy of the Holy Mount monasteries and one of the most important spiritual and cultural centers of Serbian people, was founded in 1199 and was the centre of Medieval Serbia for a long time. Even today, its rich treasuries contain a precious collection of the art works from 13 th to 18 th century [3].

On Holy Mount, in Hilandar, many buildings within the monastery complex have a slate roof covering: overnight-stay houses, towers (pirgs), paraklises (churches). All the overnight-stay houses were covered with slate, naturally split, very thick and almost unprocessed (Fig. 1). The slat roof covering has been preserved on some buildings. The slate roof covering was very much in use due to the fact that there was enough stone and it did not require a bigger production process (like lead). It is a natural material which needed some finishing touches and then it could be used on buildings. Stone was very much used for construction of buildings of that period and it was also used for the construction of foundations, walls, arches, and some types of stone were used for decorations and ornaments both in the facades and in the interiors. It was also used as a sub floor.

Slate roofing was done in the way that smaller plates, slightly cut, were thickly placed on the arches, in mud or in dry. The plates were almost horizontally laid with a slight fall to drain water. Each plate in the upper line

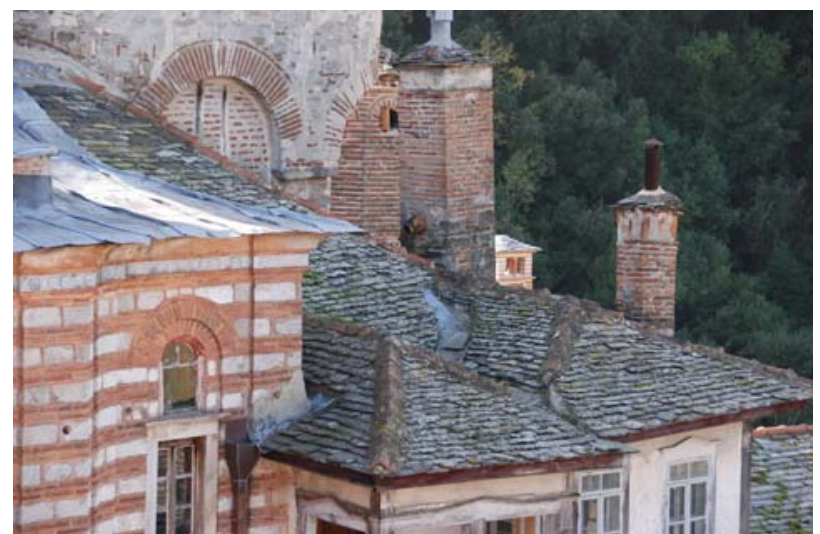

Fig. 1 Hilandar Monastery — stone as the main roofer. covered the plate joint in the lower line. This stepped back-work of slightly inclined plates prevented the water from coming into the construction. The stone used for this purpose had to be compact, thick and easy to process (suitable for stonecutting and splitting) especially into the plates 3 to $5 \mathrm{~cm}$ thick. This type of stone is called shale or slate and it is suitable for this purpose, it is grey and without any shades. Its wide use as a roof was due to its good characteristics and its ability of easy and good splitting into plates and that is why it was mass used not only as a roof on flat surfaces but also on skew ones: arches and calottes on domes.

Smaller churches and other buildings were often covered with slate, and as the evidence of this we have remnants of slate roof cover on a number of churches of that period. Slate tiles on arched surfaces is done with smaller plates which were either thickly placed directly on a dry arch surface or mud was used for pointing. Instead of mud, lime mortar or lime mortar with Santorin were also used as binders for pointing among the slats. The plates were laid almost horizontally with a slight out-downwards fall, for draining the water out form the roof surface. The slate had irregular shape, they were slightly cut and 2 to 3 $\mathrm{cm}$ thick. Due to this way of roofing, the shape of domes and arches was not changed because they received just a stone covering, but they also received a significant load because the stone was rather heavy. The examples of this kind of roofing are: St. Archangel Church (Fig. 2), St.Triphun, Holy Trinity skit, St. Sava

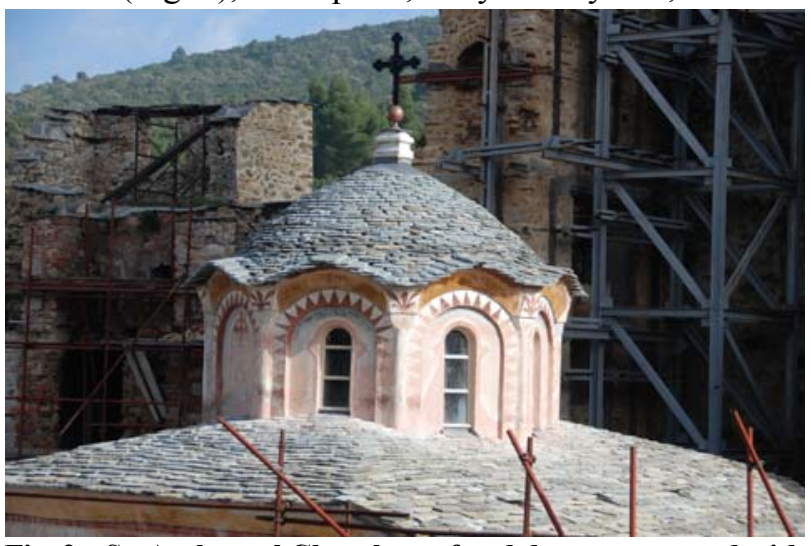

Fig. 2 St. Archangel Church, roof and dome re-covered with stone. 
paraklis and others within Hilandar Monastery on Holy Mount. Today a large number of overnight-stay buildings, kelias (flats for monks) and skits (types of monasteries) on Holy Mount have slat roof covering.

The slate, except directly on the arches, were also laid on the chestnut tree boarding placed over the wood roof construction. This roof construction had to be very strong because it carried this heavy roof cover.

Considering the fact that it was almost impossible to completely prevent water penetration through the covering because of the strong winds blowing from the sea direction in winter months, some extra measures needed to be done to prevent possible leaking or "humidity" penetration through the roof and into the inner space in use. At the time when these buildings were erected, a loft was not used so over the wood loft construction and within the loft, karatavan - a mud layer which could absorb possible water due to leaking — was made.

Since Hilandar Monastery is situated on the peninsula of Athos in the Aegean Sea, the strong winds blowing from the sea direction and the humidity they bring along penetrated deep into the walls and arches of these buildings and so damaging the paintings on the walls and arches. The whole wall surfaces, arches, church domes were painted in "al fresco" technique, that is, painted in earth colours on green mortar, so the colour dried as the mortar dried and in that way it became consistent and unchangeable.

The slate roof covering, in most cases, could not prevent leaking and penetration of humidity through the church arches and domes. In that way the frescos painted inside these buildings were directly endangered. Noticing the damage to paintings in churches and other buildings, the replacement of the original slate covering and recovering of the arches and roofs with lead slate, as the best but the most expensive solution, was started way back in the Middle Ages. For this reason, the original materialization and appearance of some buildings were changed.

\section{The Application of Modern Principles of Double Ventilated Roofs with Stone}

The tendency in retaining the slate roof covering in some buildings and keeping the appearance of these monuments as well as the reuse of stone as an authentic covering material is possible only by the application of the modern principles of double ventilated roofs. In this way it would be possible to keep the original cover or to replace the existing cover with the authentic one, but only following some necessary demands and principles of contemporary construction physics, and they are:

- ventilation just above the arch which would enable the ventilation of the existing arch construction, usually covered in frescos centuries old and priceless;

- ventilation of the final roof covering, that is creating the possibility of constant air circulation above the waterproofing and below the covering, and the possibility of drying of any humidity and leakage [4].

The suggestion for reconstruction of this covering, following the demands of contemporary construction physics is done in the way described in Fig. 3:

(1) laths $3 / 5 \mathrm{~cm}$ - are placed vertically to the eaves, that is in the direction of water draining, and over the existing arch construction;

(2) sheathing $2.4 \mathrm{~cm}$ over the laths;

(3) a standby waterproofing - waterproof paper laid over the sheathing;

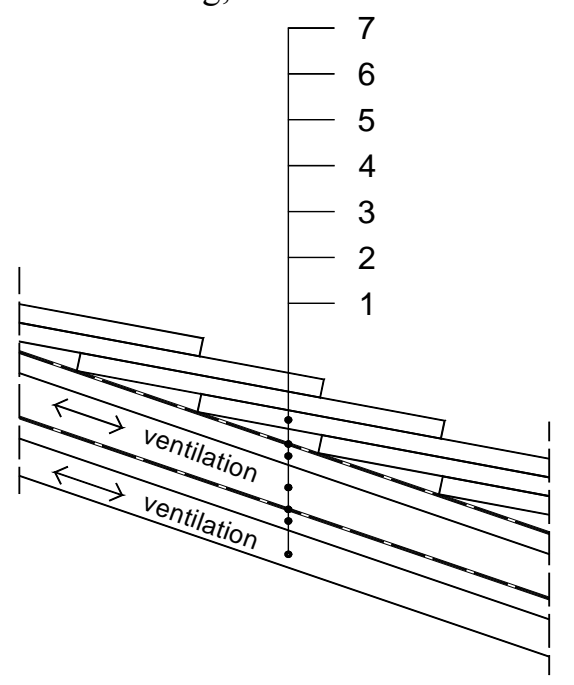

Fig. 3 Suggestion for reconstruction of this covering with stone. 
(4) laths $3 / 5 \mathrm{~cm}$ - placed vertically to the eaves, that is in the direction of water draining, and over the shearing covered with the standby waterproofing;

(5) sheathing $2.4 \mathrm{~cm}$ over the laths;

(6) waterproofing - covered with fine gritting material, and it is done over the sheathing;

(7) slate in mortar - laid over the sheathing and waterproofing.

In this way, both the ventilation of the arch itself under which the frescos are and the ventilation of the stone covering (above a waterproofing layer) are made possible. That is, drying out the condensation appearing in the lower part of slates in the early morning hours and at the same time drying out the humidity caused by the leaking between the slates. Applying the modern principles of double ventilated roofs using stone as the main roofer performed in this way, the conservation of frescos more than nine centuries old as well as the successful reconstruction of medieval buildings of priceless worth will be possible as a way of contribution to the whole world cultural inheritance.

The slate end on the eaves, in the way that the individual slate are "slightly" cut and with no separate horizontal draining canals (gutters), allowing the free inflow of air under the eaves and free air circulation among wood laths placed vertically to the eaves, along with the unavoidable placing air ducts at a ridge. In this way free air circulation from the eaves towards the ridge would be possible (Fig. 4).

This principle of covering with slates with double-ventilated roofer was used for the first time in the reconstruction and rebuilding of the existing building called "Senara", in the vicinity of the walls of Hilandar Monastery complex.

\section{Conclusions}

The replacement of worn-out and damaged slate on the roofs that still have stone covering as well as recovering of the roofs whose original slate roofer, in the meantime, was replaced with some other (mission tiles, clay tiles or lead slats), applying the modern principles of double ventilated roofs, will bring back the original look to the old overnight-stay buildings, skits and other centuries old buildings (Fig. 5).

In this way it is contributed to the protection and enrichment of the world cultural heritage. In addition to the above listed examples of rehabilitation and reconstruction of medieval buildings these modern principles of stone roofers may be applied to newly built facilities (Fig. 6), which will contribute to their fitting into the ambient unit, preservation and improvement.

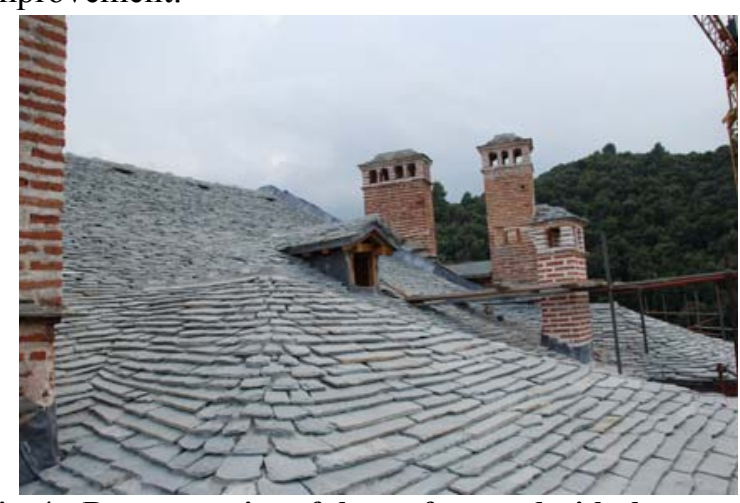

Fig. 4 Reconstruction of the roof covered with slate.

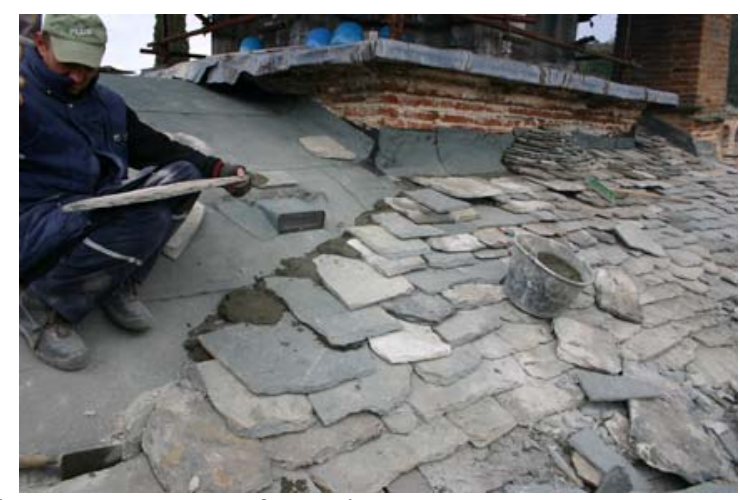

Fig. 5 The slate roof covering.

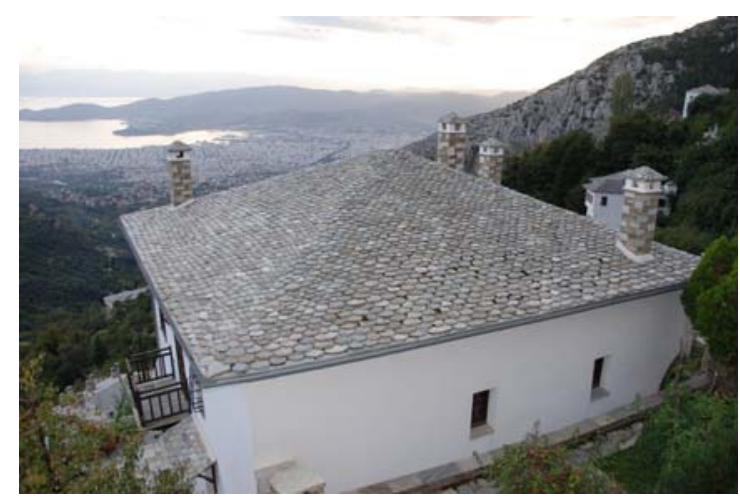

Fig. 6 Newly built facility covered with slate, Volos, Greece. 


\section{References}

[1] S. Nenadović, Building Technology in Medievel Serbia, Prosveta, Belgrade, 2003, p. 444.

[2] R. Findrik, Heritage of Raska, Vol. 2, Institute for the Protection of Cultural Monuments of Kraljevo, Kraljevo, 1980, pp. 223-225. (in Latin)
[3] V. Korać and M. Kovačević, Hilandar Monastery, Palaces and Fortifications, Serbian Institute for Protection of Cultural Monuments, Serbian Academy of Sciences and Arts, Belgrade, 2004, p. 11.

[4] P. Fasio, H. Ge and J. Rao, Research in Building Physic and Building Engineering, Taylor \& Francis, 2006, pp. 489-493. 